\title{
水曲柳和落叶松不同根序之间细根直径的变异研究
}

\author{
王向荣 ${ }^{1}$ 王政权 ${ }^{1 *}$ 韩有志 ${ }^{1,2}$ 谷加存 ${ }^{1}$ 郭大立 $^{3}$ 梅 莉 $^{1}$ \\ （1 东北林业大学林学院,哈尔滨 150040）（2 山西农业大学林学院, 山西太谷 030801） \\ (3 北京大学环境学院生态学系, 北京 100871)
}

\begin{abstract}
摘 要 细根直径大小和根序高低对细根寿命和周转估计具有重要的影响, 研究不同根序之间的直径变异对认识 细根直径与根序的关系具有重要意义。该文根据 Pregitzer 等 (2002) 提供的方法, 研究了位于东北林业大学帽儿山 实验林场尖砬沟森林培育实验站 17 年生水曲柳( Fraxinus mandshurica) 和落叶松 (Larix gmelinii) 人工林细根 $1 \sim 5$ 级 根序的平均直径的变化、直径的最小值和最大值范围、直径的变异系数。结果表明, 水曲柳和落叶松细根直径 $<2$ $\mathrm{mm}$ 时, 包含 5 个根序, 随着根序由小到大的增加, 细根直径也在增大。各根序平均直径之间, 存在较大的差异。在 同一根序内, 细根直径范围很大, 水曲柳和落叶松一级根最小直径均 $<0.20 \mathrm{~mm}$, 最大直径分别 $<0.50 \mathrm{~mm}$ (水曲柳) 和 $<0.70 \mathrm{~mm}$ (落叶松) 左右。 $2 \sim 3$ 级根序直径最小值在 $0.20 \sim 0.30 \mathrm{~mm}$ 之间, 最大值 $\leqslant 1.0 \mathrm{~mm}$. 5 级根直径最小值 $<1.0 \mathrm{~mm}$, 最大值超过 $2.0 \mathrm{~mm}$ 。随着根序等级增加, 直径变异系数增大。一级根序的直径平均变异系数 $<10 \%, 2$ $\sim 3$ 级根序直径平均变异系数在 $10 \% \sim 15 \%$ 左右, $4 \sim 5$ 级根序直径的平均变异系数在 $20 \% \sim 30 \%$ 之间。因此, 在 细根寿命与周转研究过程中, 必须同时考虑直径和根序对细根的寿命估计的影响。
\end{abstract}

关键词 细根直径 细根根序 细根寿命 细根周转 水曲柳 落叶松

\section{VARIATIONS OF FINE ROOT DIAMETER WITH ROOT ORDER IN MANCHURIAN ASH AND DAHURIAN LARCH PLANTATIONS}

\author{
WANG Xiang-Rong ${ }^{1}$ WANG Zheng-Quan ${ }^{1}{ }^{*}$ HAN You-Zhi ${ }^{1,2}$ GU Jia-Cun ${ }^{1}$ GUO Da-Li ${ }^{3}$ and MEI Li ${ }^{1}$ \\ (1 School of Forestry, Northeast Forest University, Harbin 150040, China) \\ (2 School of Forestry, Shanxi Agricultural University, Taigu, Shanxi 030801, China) \\ (3 Department of Ecology, Peking University, Beijing 100871, China)
}

Abstract Fine root life-span and turnover play an important role in carbon allocation and nutrient cycling in forest ecosystems because of high levels of fine root production and consequent mortality and decomposition. Fine roots typically are defined as having the following characteristics: less than $1 \mathrm{or} 2 \mathrm{~mm}$ in diameter; short life-span; and greater efficiency in accessing belowground resources than large diameter roots. However, when categorizing roots by diameter size, the position of an individual root on the complex lateral branching pattern has often been ignored, and our knowledge about relationships between branching order and root function is limited. More recently, studies on root order have found that first-order fine roots at the distal end of a root system, which has the primary function of nutrient uptake rather than storage and transport, are thinner in root diameter and have higher tissue nitrogen $(\mathrm{N})$ concentrations, higher maintenance respiration rates, and lower total nonstructural carbohydrate ( TNC) concentrations. Thus, the smaller diameter roots have a shorter lifespan in contrast to higher order roots (which are coarser roots with larger diameter). Although either approach (diameter or root order) is reasonable to use in fine root studies, estimates of fine root life-span or turnover are much more variable when using root diameters because of the large variation in diameter sizes. The objectives of this study were (1) to examine variations of fine root diameter and diameter range (minimum-maximum) as a function of branching order from first order to fifth order; and (2) to determine the relationship between fine root diameter and root branching order and soil resource availability using two tree species, Manchurian ash (Fraxinus mandshurica) and Dahurian larch (Larix gmelinii).

This research was conducted in Maoershan Forest Research Station $\left(45^{\circ} 21^{\prime}-45^{\circ} 25^{\prime} \mathrm{N}, 127^{\circ} 30^{\prime}-127^{\circ}\right.$ $34^{\prime}$ E) owned by Northeast Forestry University in Harbin, Heilongjiang, China. Both ash and larch forests were planted in 1986. In each plantation, we established three $20 \mathrm{~m} \times 30 \mathrm{~m}$ plots at an elevation of $506 \mathrm{~m}$. On May 15, July 15 and September 15 of 2003, three small intact segments of the fine root system were exca- 
vated carefully at a random location in each plot. Soil blocks $(20 \mathrm{~cm} \times 20 \mathrm{~cm} \times 10 \mathrm{~cm})$ were excavated from the sties at depth of $0 \sim 10 \mathrm{~cm}$ and $11 \sim 20 \mathrm{~cm}$. All intact root segments were collected from each block. Once excavated, the intact segments were put into plastic bags with ice and stored at a temperature of $0 \sim 2{ }^{\circ} \mathrm{C}$. In the laboratory, each individual root was dissected by branching order beginning with the distal end of the root system (labeled as the first-order) increasing sequentially with each branch from the first to higher order roots . After the dissection, length, diameter and dry weight of a given order were determined.

The results showed that mean diameters of fine roots were significantly different $(p<0.001)$ among orders with the diameter increasing regularly from first-order to fifth-order branches in both species. The mean diameter of first-order roots was $0.26 \mathrm{~mm}$ for ash and $0.34 \mathrm{~mm}$ for larch, and fifth-order roots had average diameters of $1.54 \mathrm{~mm}$ and $1.70 \mathrm{~mm}$ for ash and larch, respectively. If fine roots were defined as having a diameter less than 1-2 mm, five orders of ash and four orders of larch would be defined as being fine roots. If the diameter of fine roots was defined as being smaller than $0.5 \mathrm{~mm}$, the first three orders of ash roots and the first two orders of larch roots would be included in the fine root population. Within the same root order, there was variation within fine root diameters and there were differences between the two species. The diameter ranges of the fine roots from first order to fifth order were $0.15-0.58,0.18-0.70,0.26-1.05,0.36-1.43$, and $0.71-2.96 \mathrm{~mm}$ for ash, and $0.17-0.76,0.23-1.02,0.26-1.10,0.38-1.77$, and $0.84-2.80 \mathrm{~mm}$ for larch. The mean coefficient of variation in first-order roots was less than $10 \%$, second- and third-order was $10 \%-20 \%$, fourth- and fifth-order was $20 \%-30 \%$. Thus variation in root diameter also increased with increasing root order.

These results suggest that "fine roots", which are traditionally defined as an arbitrary diameter class (i. e., $<2 \mathrm{~mm}$ in diameter), may be too large a size class when compared to the finest roots. The finest roots have much shorter life-spans than larger diameter roots; however, the larger roots are still considered a component of the fine root system. Root order also is important to root life-span, because variation in diameters among roots within the same order is large and diameters varied from $<0.2 \mathrm{~mm}$, to $0.2-0.5 \mathrm{~mm}$ and to $>0.5 \mathrm{~mm}$ even in the first-order roots. Differences in the life-span between root diameter and root order affect estimates of root turnover. Therefore, based on this study, both diameter and order should be considered when estimating fine root life-span and turnover.

Key words Fine root diameter, Root order, Life-span, Turnover, Fraxinus mandshurica, Larix gmelinii

细根 (直径 $<2 \mathrm{~mm}$ ) 的周转在森林生态系统 $\mathrm{C}$ 分配和养分循环中发挥重要作用 (Fahey \& Hughes, 1994; Eissenstat \& Yanai, 1997; Gill \& Jackson, 2000)。 为了研究方便, 通常将直径 $<1 \mathrm{~mm}$ 或 $2 \mathrm{~mm}$ 的根划 分为细根, 但是这种划分忽略了细根生长的顺序和 位置 (即根序 Root order), 导致细根寿命和周转估计 不准确 (Pregitzer et al ., 1997)。Pregitzer 等(2002)和 Wells 等 (2002)研究表明, 在直径 $\leqslant 2 \mathrm{~mm}$ 的细根当 中, 它们的寿命存在明显差异, 原因是根序的不同。 生长在根系末端的一级根序的细根木质化程度较 低, 主要生理功能是吸收养分和水分, 最容易死亡, 而高级根序的细根木质化程度较高, 主要起运输作 用, 寿命较长 (Eissenstat \& Yanai, 2002; 梅莉等, 2004)。如桃树 (Prunus persica) 林一级根序细根 (平 均直径 $0.33 \mathrm{~mm}$ ) 平均寿命 $100 \mathrm{~d}$, 高级根序 (平均直 径 $0.47 \mathrm{~mm}$ )平均寿命 $242 \mathrm{~d}$ (Wells et al ., 2002)。很 明显, 细根寿命估计的差异主要是由细根直径的大 小和根序的不同引起的 (Eissenstat \& Yanai, 2002)。 因此, 细根根序与寿命关系已经成为细根周转机理
研究的重要问题 (Wells \& Eissenstat, 2003), 是对以 直径为基础的细根周转研究的挑战。

分支 (Branching order) 是根系最基本的构型特征 (Fitter \& Stickland, 1992), 分支的顺序构成根序, 代 表根系不同发育阶段。由于土壤养分和水分的空间 异质性会导致细根结构和功能的可塑性, 同一根序 的细根直径可能会有较大的差异 (Pregitzer et al., 1997; Guo et al., 2004), 目前还不清楚这种差异与 根序等级的关系以及是否会影响细根寿命。为此, 本研究的目的是通过水曲柳 (Fraxinus mandshurica) 和落叶松 (Larix gmelinii) 人工林细根一级到五级根 序的直径变化, 研究细根根序与直径变异的关系、土 壤养分和水分的有效性对直径变异的影响, 为研究 细根根序和直径对寿命的影响提供基础。

\section{1 研究方法}

\section{1 研究林分}

研究地点位于东北林业大学帽儿山实验林场 $\left(45^{\circ} 21^{\prime} \sim 45^{\circ} 25^{\prime} \mathrm{N}, 127^{\circ} 30^{\prime} \sim 127^{\circ} 34^{\prime} \mathrm{E}\right.$ ) 尖砬沟森林 
培育实验站。该地区属温带大陆性季风气候, 年平 均温度 $2.8{ }^{\circ} \mathrm{C}, 1$ 月平均温度 $-19.6{ }^{\circ} \mathrm{C}, 7$ 月平均温 度 $20.9{ }^{\circ} \mathrm{C}$ 。年降雨量 $723 \mathrm{~mm}, \geqslant 10{ }^{\circ} \mathrm{C}$ 的积温 $2526{ }^{\circ} \mathrm{C}$, 生长季 $120 \sim 140 \mathrm{~d}$ 。试验标准地分别设置 在海拔 $480 \sim 500 \mathrm{~m} 、 17$ 年生的水曲柳和落叶松人工 纯林内, 标准地面积 $20 \mathrm{~m} \times 30 \mathrm{~m}$, 重复 3 次, 两个树 种共 6 块标准地。林下土壤为暗棕色森林土, 立地 条件相对一致。

\section{2 根系和土壤取样}

分别于 2003 年 5 月 15 日、7 月 15 日和 9 月 15 日进行 3 次采样, 为了取到比较完整 (含有 6 级根以 上)的根系, 采用与 Pregitzer 等 (2002) 相同的研究方 法, 用平板利铲在每块水曲柳标准地内随机选取 3 个样点, 每个样点分 $\mathrm{A} 、 \mathrm{~B}$ 两层 $(0 \sim 10 \mathrm{~cm}, 11 \sim 20$ $\mathrm{cm}$ ) 分别取 $20 \mathrm{~cm} \times 20 \mathrm{~cm} \times 10 \mathrm{~cm}$ 深土柱, 落叶松标 准地随机选取 4 个样点, 取样方法与水曲柳相同。 取出的土柱放在塑料布上, 小心去掉根系上的土壤, 仔细检取完整的根系, 编号装入塑料袋, 对于不完整 的根系和死根也分别编号放入另一塑料袋内, 然后 放置在 $1 \sim 3{ }^{\circ} \mathrm{C}$ 冷咜藏箱内。在每一土层根系取样 同时, 取出该土层土壤 $200 \mathrm{~g}$ 左右 (鲜重), 编号并装 入塑料袋中。全部样品当天运回实验室放入 $-20{ }^{\circ} \mathrm{C}$ 冰箱保存。每次取样前用温度计测定样地 土层深度约 5 和 $15 \mathrm{~cm}$ 处的土壤温度, 并记录。

\section{3 根序测定和土壤分析}

在实验室, 用 $2 \sim 3{ }^{\circ} \mathrm{C}$ 的去离子水洗去根系上的 土壤颗粒和杂质, 然后放在直径 $15 \mathrm{~cm}$ 、装有去离子 水冰块的培养血中, 在低温下 $\left(2 \sim 3{ }^{\circ} \mathrm{C}\right)$ 区分各等级 的细根。依据 Pregizter 等 (2002) 根序分级方法, 对 每一取样点的根系, 分成若干根段 (Root segment), 按
根段进行分级。将根系末梢的根定为一级细根, 然 后是二级细根、三级细根等, 一直区分到五级细根 （图 1)。用镊子取下每一个根, 放入装有冰水的培 养血中, 查数每一等级细根的数量。同时在装有测 微尺的显微镜 $(\times 10)$ 下, 测定它们的长度和直径 $($ 精 确到 $0.01 \mathrm{~mm}$ )。把同一树种同一根段同一个根序 的根放在一起, 在尽可能短的时间内, 将每一根段的 样品测完并在 $70{ }^{\circ} \mathrm{C}$ 下 $24 \mathrm{~h}$ 烘干、称重 $(0.0001 \mathrm{~g})$ 。 不完整的细根用同样的方法进行测定。五级以上的 根 (不包括五级根) 仅烘干测定生物量 $(0.000 \mathrm{lg}$ )。 并分树种、根序等级分别保存在封口塑料瓶中。各 土层养分和水分分析采用刘光崧等(1996)提供的方 法。

\section{4 数据分析}

本研究平均每次取样、每个样点 $(20 \mathrm{~cm} \times 20 \mathrm{~cm}$ $\times 10 \mathrm{~cm}$ )测定的水曲柳 5 个等级根序细根共 16176 个( $0 \sim 10 \mathrm{~cm}$ 土层) 和 4522 个( $11 \sim 20 \mathrm{~cm}$ 土层); 落 叶松平均 5 个等级根序细根共 $4900(0 \sim 10 \mathrm{~cm}$ 土 层) 个和 1294 个( $11 \sim 20 \mathrm{~cm}$ 土层)。其中一级根占 $85 \%$, 二级根占 $10 \%$, 三级根占 $3 \%$, 四级根占 $1.8 \%$,五级根占 $0.2 \%$ 。首先计算两个树种不同季 节各级根序的平均直径、变异系数、最大值和最小 值, 然后采用方差分析方法检验不同根序之间、同一 根序不同土层之间细根直径的差异, 并且分析土壤 养分和水分的有效性以及土壤温度对细根直径变异 的影响。

\section{2 研究结果}

2.1 各级根序的平均直径

水曲柳和落叶松两个树种的一级细根平均直径

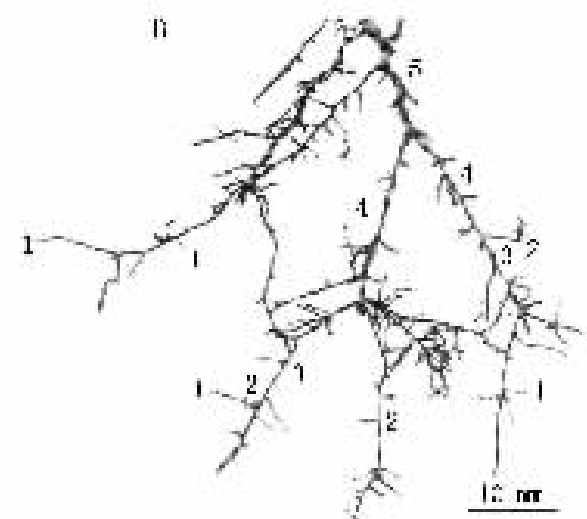

图 1 水曲柳 (A) 和落叶松 (B) 根系分支结构照片, 数字代表 1 5 级根序 
表 1 水曲柳和落叶松不同根序的平均直径

Table 1 Mean diameter of fine roots among the first five orders in Fraxinus mandshurica and Larix gmelinii trees

\begin{tabular}{|c|c|c|c|c|c|c|}
\hline \multirow{3}{*}{\multicolumn{2}{|c|}{$\begin{array}{c}\text { 土层 } \\
\text { Soil depth } \\
(\mathrm{cm})\end{array}$}} & \multicolumn{5}{|c|}{ 细根平均直径 Mean diameters of fine roots } \\
\hline & & 一级 & 二级 & 三级 & 四级 & 五级 \\
\hline & & First-order & Second-order & Third-order & Fourth-order & Fifth-order \\
\hline \multicolumn{7}{|c|}{ 水曲柳 Fraxinus mandshurica } \\
\hline \multirow[t]{2}{*}{5 月 May } & $0 \sim 10$ & $0.266(0.005)$ & $0.363(0.020)$ & $0.468(0.018)$ & $0.862(0.051)$ & $1.788(0.116)$ \\
\hline & $11 \sim 20$ & $0.269(0.009)$ & $0.349(0.013)$ & $0.493(0.026)$ & $0.930(0.063)$ & $2.317(0.398)$ \\
\hline \multirow[t]{2}{*}{7 月 July } & $0 \sim 10$ & $0.242(0.006)$ & $0.326(0.025)$ & $0.410(0.020)$ & $0.673(0.045)$ & $1.287(0.118)$ \\
\hline & $11 \sim 20$ & $0.245(0.006)$ & $0.337(0.015)$ & $0.417(0.028)$ & $0.663(0.046)$ & $1.408(0.039)$ \\
\hline \multirow[t]{2}{*}{9 月 Sept. } & $0 \sim 10$ & $0.276(0.008)$ & $0.384(0.010)$ & $0.470(0.019)$ & $0.642(0.025)$ & $1.190(0.026)$ \\
\hline & $11 \sim 20$ & $0.277(0.009)$ & $0.376(0.014)$ & $0.461(0.015)$ & $0.645(0.021)$ & $1.290(0.055)$ \\
\hline \multirow[t]{2}{*}{ 平均 Mean } & $0 \sim 10$ & $0.261(0.006)$ & $0.358(0.019)$ & $0.449(0.019)$ & $0.726(0.040)$ & $1.422(0.087)$ \\
\hline & $11 \sim 20$ & $0.264(0.008)$ & $0.354(0.014)$ & $0.457(0.023)$ & $0.746(0.043)$ & $1.672(0.164)$ \\
\hline \multicolumn{7}{|c|}{ 落叶松 Larix gmelinii } \\
\hline \multirow[t]{2}{*}{5 月 May } & $0 \sim 10$ & $0.328(0.008)$ & $0.417(0.018)$ & $0.533(0.020)$ & $0.868(0.047)$ & $2.103(0.206)$ \\
\hline & $11 \sim 20$ & $0.330(0.005)$ & $0.430(0.021)$ & $0.659(0.027)$ & $1.029(0.040)$ & $2.105(0.151)$ \\
\hline \multirow[t]{2}{*}{7 月 July } & $0 \sim 10$ & $0.308(0.005)$ & $0.450(0.017)$ & $0.530(0.027)$ & $0.813(0.045)$ & $1.551(0.104)$ \\
\hline & $11 \sim 20$ & $0.312(0.007)$ & $0.434(0.013)$ & $0.576(0.031)$ & $0.965(0.089)$ & $1.759(0.157)$ \\
\hline \multirow[t]{2}{*}{9 月 Sept. } & $0 \sim 10$ & $0.369(0.007)$ & $0.424(0.009)$ & $0.507(0.015)$ & $0.647(0.025)$ & $1.140(0.051)$ \\
\hline & $11 \sim 20$ & $0.389(0.006)$ & $0.467(0.011)$ & $0.597(0.026)$ & $0.831(0.047)$ & $1.559(0.103)$ \\
\hline \multirow[t]{2}{*}{ 平均 Mean } & $0 \sim 10$ & $0.335(0.007)$ & $0.431(0.015)$ & $0.532(0.020)$ & $0.776(0.039)$ & $1.598(0.120)$ \\
\hline & $11 \sim 20$ & $0.344(0.006)$ & $0.443(0.015)$ & $0.611(0.028)$ & $0.942(0.059)$ & $1.808(0.137)$ \\
\hline
\end{tabular}

括号内数字为标准差 Values in parentheses are standard errors

表 2 水曲柳和落叶松各级根序的细根直径 ( $\mathbf{m m}$ ) 最小值和最大值

Table 2 Diameter ( $\mathrm{mm}$ ) range ( min-max) of fine roots among the first five orders in Fraxinus mandshurica and Larix gmelinii trees

\begin{tabular}{|c|c|c|c|c|c|c|}
\hline \multirow{3}{*}{\multicolumn{2}{|c|}{$\begin{array}{c}\text { 土层 } \\
\text { Soil depth } \\
(\mathrm{cm})\end{array}$}} & \multicolumn{5}{|c|}{ 根序与直径最小值和最大值 Diameter range ( min-max) among the first five orders } \\
\hline & & 一级 & 二级 & 三级 & 四级 & 五级 \\
\hline & & First-order & Second-order & Third-order & Fourth-order & Fifth-order \\
\hline \multicolumn{7}{|c|}{ 水曲柳 Fraxinus mandshurica } \\
\hline \multirow[t]{2}{*}{5 月 May } & $0 \sim 10$ & $0.15 \sim 0.78$ & $0.21 \sim 0.78$ & $0.27 \sim 0.83$ & $0.38 \sim 1.73$ & $0.96 \sim 3.31$ \\
\hline & $11 \sim 20$ & $0.19 \sim 0.47$ & $0.19 \sim 0.66$ & $0.27 \sim 0.94$ & $0.43 \sim 1.51$ & $1.30 \sim 4.16$ \\
\hline \multirow[t]{2}{*}{7 月 July } & $0 \sim 10$ & $0.12 \sim 0.47$ & $0.14 \sim 0.64$ & $0.22 \sim 0.78$ & $0.33 \sim 1.31$ & $0.60 \sim 2.23$ \\
\hline & $11 \sim 20$ & $0.14 \sim 0.47$ & $0.15 \sim 0.67$ & $0.22 \sim 1.37$ & $0.32 \sim 1.37$ & $0.62 \sim 2.46$ \\
\hline \multirow[t]{2}{*}{9 月 Sept. } & $0 \sim 10$ & $0.16 \sim 0.49$ & $0.22 \sim 0.68$ & $0.29 \sim 0.88$ & $0.36 \sim 1.24$ & $0.58 \sim 2.12$ \\
\hline & $11 \sim 20$ & $0.15 \sim 0.49$ & $0.20 \sim 0.69$ & $0.32 \sim 0.84$ & $0.39 \sim 1.46$ & $0.64 \sim 2.27$ \\
\hline \multirow[t]{2}{*}{ 平均 Mean } & $0 \sim 10$ & $0.15 \sim 0.58$ & $0.19 \sim 0.70$ & $0.26 \sim 0.83$ & $0.36 \sim 1.43$ & $0.71 \sim 2.56$ \\
\hline & $11 \sim 20$ & $0.16 \sim 0.48$ & $0.18 \sim 0.67$ & $0.27 \sim 1.05$ & $0.38 \sim 1.45$ & $0.85 \sim 2.96$ \\
\hline \multicolumn{7}{|c|}{ 落叶松 Larix gmelinii } \\
\hline \multirow[t]{2}{*}{5 月 May } & $0 \sim 10$ & $0.18 \sim 0.65$ & $0.17 \sim 1.11$ & $0.24 \sim 1.07$ & $0.42 \sim 1.55$ & $1.13 \sim 3.29$ \\
\hline & $11 \sim 20$ & $0.18 \sim 0.58$ & $0.23 \sim 0.81$ & $0.35 \sim 1.06$ & $0.50 \sim 1.90$ & $1.01 \sim 3.44$ \\
\hline \multirow[t]{2}{*}{7 月 July } & $0 \sim 10$ & $0.19 \sim 0.81$ & $0.25 \sim 1.17$ & $0.26 \sim 1.01$ & $0.40 \sim 1.56$ & $0.84 \sim 2.52$ \\
\hline & $11 \sim 20$ & $0.15 \sim 0.69$ & $0.23 \sim 0.84$ & $0.28 \sim 1.06$ & $0.45 \sim 1.81$ & $0.95 \sim 2.63$ \\
\hline \multirow[t]{2}{*}{9 月 Sept. } & $0 \sim 10$ & $0.17 \sim 0.82$ & $0.26 \sim 0.77$ & $0.27 \sim 0.95$ & $0.33 \sim 1.25$ & $0.54 \sim 2.11$ \\
\hline & $11 \sim 20$ & $0.19 \sim 0.80$ & $0.22 \sim 0.89$ & $0.30 \sim 1.16$ & $0.40 \sim 1.60$ & $0.98 \sim 2.32$ \\
\hline \multirow[t]{2}{*}{ 平均 Mean } & $0 \sim 10$ & $0.18 \sim 0.76$ & $0.23 \sim 1.02$ & $0.26 \sim 1.01$ & $0.38 \sim 1.45$ & $0.84 \sim 2.64$ \\
\hline & $11 \sim 20$ & $0.17 \sim 0.69$ & $0.23 \sim 0.85$ & $0.31 \sim 1.10$ & $0.45 \sim 1.77$ & $0.98 \sim 2.80$ \\
\hline
\end{tabular}

最小 (水曲柳为 $0.26 \mathrm{~mm}$, 落叶松 $0.34 \mathrm{~mm}$ ), 五级细 根平均直径相对最大 (水曲柳为 $1.54 \mathrm{~mm}$, 落叶松为 $1.70 \mathrm{~mm}$ ), 随着根序增加平均直径增粗 (表 1 ), 平均 直径相差 $4 \sim 5$ 倍。水曲柳前 3 个根序、落叶松前 2 个根序的平均直径均 $<0.5 \mathrm{~mm}$, 两个树种的前 4 个
根序均 $<1 \mathrm{~mm}$ (落叶松 5 月 $11 \sim 20 \mathrm{~cm}$ 土层除外)。 方差分析表明,两个树种 5 个等级根序之间、不同土 层之间细根直径存在极显著差异 $(p<0.001)$ 。水曲 柳前 3 个根序、落叶松 1 级根序夏季 ( 7 月) 的平均 直径小于春季 ( 5 月)和秋季 ( 9 月)的平均直径。但 
是, 7 月平均直径与 5 月和 9 月平均直径的方差分 析显示, 两个树种仅是在一级根系之间存在显著差 异 $(p<0.05)$ 。在四到五级根序之间, 春季 ( 5 月) 的 四到五级根平均直径相对最粗, 其次是夏季 ( 7 月), 秋季 (9月)最细。如果不考虑季节和土层深度因 素, 两个树种三到二级和二到一级根序之间直径均 以 $1 / 4$ 比例减小 (表 1 )。

\section{2 各级根序平均直径的变化范围}

虽然各级根序的平均直径随着根序的增加而增 粗, 但是每一级根序直径分布范围较大 (表 2)。到四级根的直径最小值均 $<0.50 \mathrm{~mm}$, 最大值在 1.20 $\sim 1.90 \mathrm{~mm}$ 之间, 直径最小值和最大值相差近 $3 \sim 4$ 倍。其中, 水曲柳和落叶松一级根最小直径均 $<$ $0.20 \mathrm{~mm}$, 最大直径分别 $<0.50 \mathrm{~mm}$ (水曲柳) 和 $<$ $0.70 \mathrm{~mm}$ (落叶松)左右。二到三级根序直径最小值 在 $0.20 \sim 0.30 \mathrm{~mm}$ 之间, 最大值 $\leqslant 1.0 \mathrm{~mm}$ 。五级根 直径最小值 $<1.0 \mathrm{~mm}$, 最大值超过 $2.0 \mathrm{~mm}$ (在 $2.0 \sim$ $3.0 \mathrm{~mm}$ 之间)。根序等级越高, 其直径变异系数越 大(表 3)。一级根序的直径平均变异系数 $<10 \%$ ， 二到三级根序直径平均变异系数 10\% 15\%左右, 四到五级根序直径的平均变异系数在 $20 \%$ 30\% 之间 (表 3)。

\section{3 土壤资源的有效性对细根直径的影响}

林地土壤表层 $0 \sim 10 \mathrm{~cm}$ 的温度 ( 9 月除外)、水
分和有效 $\mathrm{N}$ 明显高于深度 $11 \sim 20 \mathrm{~cm}$ 的值 $(p<$ 0.05 )(表 4), 尤其是土壤中的有效 $\mathrm{N}$ 含量, 两层之 间相差 1 倍左右。土壤表层 $0 \sim 10 \mathrm{~cm}$ 的资源有效 性有利于根系的生长和发育。各根序平均直径在不 同土层之间虽然存在差异 (表 1), 但是方差分析表 明, 各根序直径平均值在 $0 \sim 10 \mathrm{~cm}$ 和 $11 \sim 20 \mathrm{~cm}$ 土 层之间的比较 (表 1 ), 则差异不显著 $(p>0.05)$ (落 叶松 9 月除外, 该月各级根序平均直径在两层之间 差异显著, $p<0.05)$, 而且直径平均最小值之间、直 径平均最大值之间的差异也均不显著 $(p>0.05)$ 。 如果考虑个体根系直径的变化, 各级根序中的单个 细根直径在 $0 \sim 10 \mathrm{~cm}$ 和 $11 \sim 20 \mathrm{~cm}$ 土层之间存在显 著差异 $(p<0.001)$ 。上述结果表明, 土壤资源有效 性对直径可塑性的影响, 仅表现在细根直径的个体 之间,在群体(平均)之间无影响。

\section{3 讨 论}

直径是根系重要的结构特征, 其粗细反映不同 的生理功能 (Fitter, 1996)。与粗根相比, 细根中通常 $\mathrm{N}$ 的浓度较高 (Pregitzer et al.,2002), 而 C 的浓度较 低 (Gordon \& Jackson, 2000)。细根可以使根系有效 的吸收土体内养分和水分, 而在形成和维持生理功 能方面投入的 C 较少 (Eissenstat, 1992), 粗根( 常常 木质化) 投入的 $\mathrm{C}$ 相对较多, 但是粗根具有较高运

表 3 水曲柳和落叶松细根直径变异系数

Table 3 Coefficients of variations in fine root diameters among the first five orders in Fraxinus mandshurica and Larix gmelinii trees

\begin{tabular}{|c|c|c|c|c|c|c|}
\hline \multirow{3}{*}{\multicolumn{2}{|c|}{$\begin{array}{c}\text { 土层 } \\
\text { Soil depth } \\
(\mathrm{cm}) \\
\end{array}$}} & \multicolumn{5}{|c|}{ 细根直径变异系数 Coefficients of variations in fine root diameters } \\
\hline & & 一级 & 二级 & 三级 & 四级 & 五级 \\
\hline & & First-order & Second-order & Third-order & Fourth-order & Fifth-order \\
\hline \multicolumn{7}{|c|}{ 水曲柳 Fraxinus mandshurica } \\
\hline \multirow[t]{2}{*}{5 月 May } & $0 \sim 10$ & 0.058 & 0.167 & 0.116 & 0.178 & 0.195 \\
\hline & $11 \sim 20$ & 0.104 & 0.108 & 0.157 & 0.204 & 0.515 \\
\hline \multirow[t]{2}{*}{7 月 July } & $0 \sim 10$ & 0.073 & 0.233 & 0.145 & 0.199 & 0.275 \\
\hline & $11 \sim 20$ & 0.074 & 0.129 & 0.201 & 0.208 & 0.082 \\
\hline \multirow[t]{2}{*}{9 月 Sept. } & $0 \sim 10$ & 0.086 & 0.079 & 0.119 & 0.116 & 0.066 \\
\hline & $11 \sim 20$ & 0.095 & 0.111 & 0.097 & 0.099 & 0.128 \\
\hline \multirow[t]{2}{*}{ 平均 Mean } & $0 \sim 10$ & 0.072 & 0.159 & 0.127 & 0.165 & 0.179 \\
\hline & $11 \sim 20$ & 0.091 & 0.116 & 0.152 & 0.170 & 0.242 \\
\hline \multicolumn{7}{|c|}{ 落叶松 Larix gmelinii } \\
\hline \multirow[t]{2}{*}{5 月 May } & $0 \sim 10$ & 0.084 & 0.150 & 0.128 & 0.188 & 0.338 \\
\hline & $11 \sim 20$ & 0.048 & 0.170 & 0.142 & 0.133 & 0.249 \\
\hline \multirow[t]{2}{*}{7 月 July } & $0 \sim 10$ & 0.056 & 0.130 & 0.176 & 0.193 & 0.233 \\
\hline & $11 \sim 20$ & 0.073 & 0.104 & 0.189 & 0.321 & 0.309 \\
\hline \multirow[t]{2}{*}{9 月 Sept. } & $0 \sim 10$ & 0.047 & 0.138 & 0.184 & 0.242 & 0.316 \\
\hline & $11 \sim 20$ & 0.055 & 0.078 & 0.149 & 0.195 & 0.229 \\
\hline \multirow[t]{2}{*}{ 平均 Mean } & $0 \sim 10$ & 0.062 & 0.139 & 0.163 & 0.208 & 0.296 \\
\hline & $11 \sim 20$ & 0.059 & 0.117 & 0.160 & 0.216 & 0.262 \\
\hline
\end{tabular}


表 4 水曲柳和落叶松不同土壤层次温度、水分和 $\mathbf{N}$ 有效性

Table 4 Soil temperature, moisture and nitrogen availability of different soil depths in Fraxinus mandshurica and Larix gmelinii trees

\begin{tabular}{|c|c|c|c|c|}
\hline & $\begin{array}{c}\text { 土层 } \\
\text { Soil depth }(\mathrm{cm})\end{array}$ & $\begin{array}{c}\text { 土壤温度 } \\
\text { Soil temperature }\left({ }^{\circ} \mathrm{C}\right)\end{array}$ & $\begin{array}{c}\text { 土壤水分 } \\
\text { Soil moisture }(\%)\end{array}$ & $\begin{array}{c}\text { 土壤有效 } \mathrm{N} \\
\text { Soil nitrogen availability }\left(\mathrm{mg}^{\bullet} \mathrm{kg}^{-1}\right)\end{array}$ \\
\hline \multicolumn{5}{|c|}{ 水曲柳 Fraxinus mandshurica } \\
\hline \multirow[t]{2}{*}{5 月 May } & $0 \sim 10$ & $9.93(0.65)^{\mathrm{a}}$ & $0.55(0.02)^{\mathrm{a}}$ & $24.69(1.36)^{\mathrm{a}}$ \\
\hline & $11 \sim 20$ & $8.87(0.42)^{b}$ & $0.63(0.01)^{b}$ & $11.39(0.71)^{\mathrm{b}}$ \\
\hline \multirow[t]{2}{*}{7 月 July } & $0 \sim 10$ & $16.95(0.45)^{\mathrm{a}}$ & $0.52(0.01)^{\mathrm{a}}$ & $26.75(1.33)^{\mathrm{a}}$ \\
\hline & $11 \sim 20$ & $16.01(0.47)^{\mathrm{b}}$ & $0.59(0.02)^{\mathrm{b}}$ & $12.57(0.89)^{\mathrm{b}}$ \\
\hline \multirow[t]{2}{*}{9 月 Sept. } & $0 \sim 10$ & $10.05(0.08)^{\mathrm{a}}$ & $0.57(0.01)^{\mathrm{a}}$ & $18.99(1.41)^{\mathrm{a}}$ \\
\hline & $11 \sim 20$ & $10.50(0.09)^{\mathrm{a}}$ & $0.67(0.01)^{\mathrm{b}}$ & $9.81(0.74)^{\mathrm{b}}$ \\
\hline \multicolumn{5}{|c|}{ 落叶松 Larix gmelinii } \\
\hline \multirow[t]{2}{*}{5 月 May } & $0 \sim 10$ & $8.43(0.44)^{\mathrm{a}}$ & $0.58(0.01)^{\mathrm{a}}$ & $21.38(3.18)^{\mathrm{a}}$ \\
\hline & $11 \sim 20$ & $7.73(0.18)^{\mathrm{b}}$ & $0.65(0.01)^{\mathrm{b}}$ & $13.15(0.76)^{\mathrm{b}}$ \\
\hline \multirow[t]{2}{*}{7 月 July } & $0 \sim 10$ & $17.10(0.58)^{\mathrm{a}}$ & $0.61(0.06)^{\mathrm{a}}$ & $21.05(1.37)^{\mathrm{a}}$ \\
\hline & $11 \sim 20$ & $16.25(0.31)^{\mathrm{b}}$ & $0.62(0.01)^{\mathrm{a}}$ & $11.33(0.84)^{\mathrm{b}}$ \\
\hline \multirow[t]{2}{*}{9 月 Sept. } & $0 \sim 10$ & $9.85(0.42)^{\mathrm{a}}$ & $0.65(0.01)^{\mathrm{a}}$ & $18.88(1.99)^{\mathrm{a}}$ \\
\hline & $11 \sim 20$ & $10.13(0.41)^{\mathrm{b}}$ & $0.70(0.01)^{\mathrm{b}}$ & $11.64(0.92)^{\mathrm{b}}$ \\
\hline
\end{tabular}

括号内数字为标准差; $\mathrm{a}, \mathrm{b}$ 表差异显著, $p<0.05$ Values in parentheses are standard errors; $\mathrm{a}, \mathrm{b}$ are shown significant differences, $p<0.05$

输效率、免受不良环境伤害、病原菌侵染、土壤植食 性动物 (如线虫) 的啮食等 (Eissenstat \& Yanai, 1997; Forde \& Lorenzo, 2001)。由于土壤存在空间和时间 上的异质性, 许多植物根系通过调节直径的大小表 现出对环境的适应 (Fitter, 1996; Eissenstat et al., 2000; Forde \& Lorenzo, 2001)。在土壤资源有效性不 同的表层 $(0 \sim 10 \mathrm{~cm})$ 和亚表层 $(11 \sim 20 \mathrm{~cm})$ (表 4), 水曲柳和落叶松单个细根直径之间存在显著差异 $(p<0.001)$, 表层 $(0 \sim 10 \mathrm{~cm})$ 的平均直径略小于亚 表层 (11 20 cm) (表 1), 平均直径之间差异不显著 $(p>0.05)$ 。这也说明, 土壤资源的有效性对单个细 根直径的影响远远大于对平均直径的影响, 根系往 往通过个体直径的变化来适应土壤的异质性( Eissenstat \& Caldwell, 1988; Friend et al., 1990; Eissenstat, 1992; 吴 楚等, 2004)。

细根的功能不但表现在直径方面, 而且主要通 过分支根序表现出来 (Fitter, 1996; Pregitzer et al., 1997)。依据根序发育的顺序, Pregitzer 等 (2002) 对 北美大陆 4 种阔叶树种和 5 种针叶树种的前 3 个根 序的细根研究表明, 随着根序由小到大的增加, 根系 直径增加、根细胞中 $\mathrm{C}$ 浓度提高、 $\mathrm{N}$ 浓度降低。因 此, 低级根序死亡的概率大于高级根序 ( Pregitzer et $a l$, 2002; Wells et al., 2002)。由于细根衰老的顺序 可能与发育的顺序相反 (Burton et al . 2000; Pregitzer et al ., 1997, 2002), 以直径 $<2 \mathrm{~mm}$ (或 $<1 \mathrm{~mm}$ ) 的根 为细根周转研究对象, 可能会产生较大的误差。本 研究表明, 直径 $\leqslant 2 \mathrm{~mm}$ 时, 水曲柳和落叶松的细根 通常包含五级根序( 表 1)。由五到一级根序代表根
序不同的发育阶段。当直径 $<0.5 \mathrm{~mm}$, 水曲柳包含 前 3 个根序, 落叶松包含前 2 个根序, 直径 $<1 \mathrm{~mm}$ 时, 包含两树种前 4 个根序。随着根序的增加, 平均 直径增大。但是, 各级根序之间、同一级根序之间直 径变异范围相差几倍 (表 2), 在一级根序中既含有 直径 $<0.2 \mathrm{~mm}$ 的细根, 又包括 $>0.5 \mathrm{~mm}$ 的细根, 二 级根序的直径在 $0.2 \sim 1 \mathrm{~mm}$ 之间, 就是五级根序中 直径也有 $<1 \mathrm{~mm}$ 和 $>2 \mathrm{~mm}$ 的根系存在(表 2)。虽 然属于同一根序, 因直径不同, 单个细根之间的寿命 差异可能很大。Wells 等 (2002) 对美国佛吉尼亚桃 树林细根寿命分析证实, 直径 $<0.25 \mathrm{~mm}$ 的一级根 寿命中值是 $74 \mathrm{~d}$, 直径在 $0.25 \sim 0.5 \mathrm{~mm}$ 的一级细根 寿命中值为 $121 \mathrm{~d}$, 而直径 $>0.5 \mathrm{~mm}$ 的一级细根寿 命中值 $213 \mathrm{~d}$ 。一级细根由于直径不同, 寿命相差 3 倍。表 1 和表 2 的数据显示, 如果细根研究过程中 仅考虑根序而忽略直径, 同样对细根周转估计会产 生较大的误差。

从根系发育顺序、衰老过程和生理功能方面考 虑, 采用 “根序派” (相对于 “直径派”) 的观点和方法 研究细根周转问题似乎更有道理。但是由于细根的 数量巨大, 采用根序的方法研究细根的周转在取样 方面会带来无法克服的困难, 因为实际上细根研究 不可能一个个甄别某个细根属于哪一个根序。现在 的问题是怎样使“根序派”和“直径派”的观点在一定 细根直径范围内达到“共识”。本研究的数据 (表 1 ２）显示, 直径越细, 包含的根序越少, 这为“根序 派”和“直径派”的“共识”提供了一个思路。当细根 直径小于某个数值时 (包含前 $2 \sim 3$ 个根序), 一级根 
序的数量、长度和生物量占绝大部分的比例, 采用这 个数值作为细根直径划分标准, 可能使细根寿命和 周转研究中的误差显著减少。因此, 需要深入研究 细根直径与根序的关系。

\section{4 结 论}

1）水曲柳和落叶松细根直径 $<2 \mathrm{~mm}$ 时, 包含 5 个根序, 当直径 $<0.5 \mathrm{~mm}$, 水曲柳包含前 3 个根序, 落叶松包含前 2 个根序, 直径 $<1 \mathrm{~mm}$ 时, 包含两树 种前 4 个根序。随着根序由小到大的增加, 细根直 径也在增大。各根序平均直径之间, 存在较大的差 异。在同一根序内, 细根直径范围很大, 水曲柳和落 叶松一级根最小直径均 $<0.20 \mathrm{~mm}$, 最大直径分别 $<0.50 \mathrm{~mm}$ (水曲柳) 和 $<0.70 \mathrm{~mm}$ (落叶松)左右。 二到三级根序直径最小值在 $0.20 \sim 0.30 \mathrm{~mm}$ 之间, 最大值 $\leqslant 1.0 \mathrm{~mm}$ 。五级根直径最小值 $<1.0 \mathrm{~mm}$, 最 大值超过 $2.0 \mathrm{~mm}$ 。

2) 随着根序等级增加, 直径变异系数增大。一 级根序的直径平均变异系数 $<10 \%$, 二到三级根序 直径平均变异系数 $10 \% \sim 15 \%$ 左右, 四到五级根序 直径的平均变异系数在 $20 \% \sim 30 \%$ 之间。表层 ( 0 $\sim 10 \mathrm{~mm}$ ) 和亚表层 $(11 \sim 20 \mathrm{~mm}$ ) 的土壤温度、水分 和有效 $\mathrm{N}$ 对不同根序的细根平均直径无显著影响, 但是对根系个体的直径有显著影响。

3) 细根直径和根序与细根寿命具有重要关系。 在细根寿命和周转研究中, 直径越小, 寿命越短, 一 级根寿命明显小于高级根序。但是, 同一级根序因 直径不同寿命也具有较大差异。因此, 在细根寿命 与周转研究过程中, 必须同时考虑直径和根序对细 根寿命估计的影响。

\section{参 考 文 献}

Burton AJ, Pregitzer KS, Hendrick RL (2000). Relationships between fine root dynamics and nitrogen availability in Michigan northern hardwood forests. Oecologia, 125, $389-999$.

Eissenstat DM, Caldwell MM (1988). Seasonal timing of root growth in favorable microsites. Ecology, 69,870-873.

Eissenstat DM, Wells CE, Yanai RD (2000). Research review: building roots in a changing environment: implications for root longevity. New Phytologist, 147,32-42.

Eissenstat DM, Yanai RD (1997). The ecology of root lifespan. Advances in Ecological Research, 27,2 - 59.

Eissenstat DM, Yanai RD (2002). Root life span, efficiency and turnover. In: Waisel Y, Eshel A, Kafkafi U eds. Plant Roots : the Hidden Half 3rd edn. Dekker, New York, 221 - 238.

Eissenstat EM (1992). Cost and benefit of constructing roots of small diameter. Journal of Plant Nutrition, 15,763- 782 .

Fahey TJ, Hughes JW (1994). Fine root dynamics in northern hardwood forest ecosystem, Hubbard Brook experimental forest, NH. Journal of Ecology, 82,533-548.

Fitter AH, Stickland TR (1992). Architectural analysis of plant root systems III . Studies on plants under field conditions. New Phytologist, $121,243-248$.

Fitter AH (1996) . Characteristics and functions of root systems. In: Waisel, Y, Eshel E, Kafkafi U eds. Plant Roots : the Hidden Half 2nd edn. Dekker, New York, 1-20.

Forde BG, Lorenzo H (2001). The nutritional control of root development. Plant and Soil, 232,51-68.

Friend AL, Eide MR, Hinckley TA (1990). Nitrogen stress alters root proliferation in Douglas-fir seedlings. Canadian Journal of Forest Research, 20,1524-1529.

Gill RA, Jackson RB (2000). Global patterns of root turnover for terrestrial ecosystems. New Phytologist, 147,13-31.

Gordon WS, Jackson RB (2000). Nutrient concentration in fine roots. Ecology, $81,275-280$.

Guo DL, Mitchell RJ, Hendricks JJ (2004) . Fine root branch orders respond differentially to carbon source-sink manipulations in a longleaf pine forest. Oecologia, 140,450-457.

Liu GS (刘光崧), Jiang NH (蒋能慧), Zhang LD (张连第), Liu ZL (刘兆礼) (1996). Soil Physical and Chemical Analysis Description of Soil Profile (土壤理化分析与剖面描述). Standard Press of China, Beijing, 121 - 135. (in Chinese)

Mei L (梅莉), Wang ZQ (王政权), Cheng YH (程云环), Guo DL (郭大立) (2004). A review: factors influencing fine root longevity in forest ecosystems. Acta Phytoecologica Sinica (植物 生态学报), 28,704-710. (in Chinese with English abstract)

Pregitzer KS, Deforest JL, Burton AJ, Allen MF, Ruess RW, Hendrick RL (2002). Fine root architecture of nine north American trees. Ecological Monographs, 72,293-309.

Pregitzer KS, Kubiske ME, Yu CK, Hendrick RL (1997). Relationships among root branch order, carbon, and nitrogen in four temperate species. Oecologia, 111,302-308.

Wells CE, Eissenstat DM (2003). Beyond the roots of young seedlings: the influence of age and order on fine root physiology. Journal of Plant Growth Regulation, 21,324-334.

Wells CE, Glenn DM, Eissenstat DM (2002). Changes in the risk of fine-root mortality with age: a case study in peach, Prunus persica (Rosaceae). American Journal of Botany, 89,79-87.

Wu C (吴楚), Wang ZQ (王政权), Fan ZQ (范志强) (2004).

Significance of senescence study on tree roots and its advances. Chinese Journal of Applied Ecology (应用生态学报), 15, 1276 - 1280. (in Chinese with English abstract) 